\title{
An Atomic-Scale View of the Oxidation and Reduction of Supported Ultrathin FeO Islands
}

\author{
Yijia Li, Kræn C. Adamsen, Lutz Lammich, Jeppe V. Lauritsen, and Stefan Wendt* \\ Interdisciplinary Nanoscience Center (iNANO) and Department of Physics and Astronomy, \\ Aarhus University, DK-8000 Aarhus C, Denmark
}

\begin{abstract}
By means of scanning tunneling microscopy (STM) measurements we studied in situ the oxidation and reduction of $\mathrm{FeO}$ bilayer islands on $\mathrm{Au}(111)$ by oxygen $\left(\mathrm{O}_{2}\right)$ and hydrogen $\left(\mathrm{H}_{2}\right)$, respectively. The FeO islands respond very dynamically towards oxygen $\left(\mathrm{O}_{2}\right)$, with the coordinatively unsaturated ferrous (CUF) sites at the island edges being essential for $\mathrm{O}_{2}$ dissociation and $\mathrm{O}$ adatom incorporation. An STM movie obtained during oxidation reveales how further $\mathrm{O}_{2}$ molecules can dissociate after the consumption of all initially existing CUF sites though the formation of new CUF sites. In contrast, we found that $\mathrm{H}_{2}$ molecules only dissociate when vibrationally excited through the ion gauge, and only at the basal plane of $\mathrm{FeO}$ islands, implying that the CUF sites are not relevant for $\mathrm{H}_{2}$ dissociation. Our STM results reveal how excess $\mathrm{O}$ adatoms are incorporated and released in $\mathrm{O}_{2}$ and $\mathrm{H}_{2}$, and thus shed light onto the stability of inverse catalysts during a catalyzed reaction.
\end{abstract}

KEYWORDS: Iron oxide, catalysis, $\mathrm{O}$ adatom dislocation lines, $\mathrm{O}_{2}, \mathrm{H}_{2}$, vibrational excitation, dissociation, STM movies 
Nanoparticles, consisting of noble metals and transition metal oxides, are often excellent heterogeneous catalysts. ${ }^{1,2}$ Originally it was believed that the oxides are just passive supports of the actual catalysts - tiny metal particles that are distributed on the oxide support. However, with time it became clear that this traditional picture was far too simple and that the support matters. ${ }^{1,3}$ Whereas traditionally catalysis research - including wide screening of possible material combinations - has identified almost all catalysts used today in the chemical industry, a solid understanding as to why a certain material composite works well as a catalyst for a selected reaction while others do not, is hampered within this approach. Here, the surface science approach ${ }^{3}$, ${ }^{4}$ has helped to shed light onto catalyzed reactions at the atomic scale. In this approach, simplified model systems are synthesized and studied instead of the complex working catalysts, and instead of realistic reaction conditions (usually high temperatures and pressures) such model systems are studied under well-controlled conditions (often at pressures $\leq 5 \times 10^{-10}$ mbar and at low temperatures). Thus, the results obtained within the surface science approach need to be extrapolated to typical conditions in heterogeneous catalysis. Because this can be tricky, the combination of traditional catalysis studies with surface science work is very appealing and can lead to reliable results.

A successful example for such a combined approach has been published in 2010 by Fu et al. ${ }^{5}$ These authors showed that $\mathrm{Pt}(111)$-supported bilayer $\mathrm{FeO}$ islands catalyze the oxidation of $\mathrm{CO}$ at room temperature (RT). In addition, these authors showed that Pt-Fe nanoparticles with $\mathrm{FeO}$ islands on their surfaces are very active catalysts for the preferential oxidation of $\mathrm{CO}$ in excess of $\mathrm{H}_{2}$ (PROX) at $\mathrm{RT}$ or below. ${ }^{5,6}$ A so-called 'inverse catalyst ${ }^{7-10}$ was produced and shown to be active at realistic conditions. At inverse catalysts, ultrathin oxides patches cover a transition metal (TM) surface. Note that the oxide-TM interface and the oxide edges are accessible on such 
systems, and that inverse catalysts can be designed and well-studied within the surface science approach.

Regarding the bilayer $\mathrm{FeO}$ islands supported on $\mathrm{Pt}(111)$ [from now on denoted ' $\mathrm{FeO}$ is / $\mathrm{Pt}(111)]^{\prime}$, Fu et al. ${ }^{5}$ suggested that interface-confined coordinatively unsaturated ferrous (CUF) sites at the $\mathrm{FeO}$ island edges (i.e. the $\mathrm{Fe}$-edges) are essential to facilitate $\mathrm{O}_{2}$ dissociation reactions, and that the $\mathrm{O}$ adatoms created in this way can react with nearby $\mathrm{CO}$ at the $\mathrm{Pt}$ substrate. Since then, several research papers appeared that shed light onto many facets of this and related interesting phenomena. ${ }^{11-23}$ For example, a rich variety of island edge structures was identified, depending whether the preparation conditions were oxidizing or reducing. ${ }^{17,}{ }^{19}$ Whereas a combined STM / DFT study confirmed that the Fe-edges can host the catalytically active sites for CO oxidation over $\mathrm{FeO}_{\text {is }} / \mathrm{Pt}(111)$ at $\mathrm{RT},{ }^{18}$ another mechanism for higher reaction temperatures $(480 \mathrm{~K})$ was recently introduced by Zhang et al. ${ }^{23}$ These authors proposed that $\mathrm{CO}$ oxidation takes place at the interface between reduced $(\mathrm{FeO})$ and oxidized $\left(\mathrm{FeO}_{2}\right)$ phases within the oxide patches formed under reaction conditions, and that the role of the TM support is to ease the formation of the reduced phase. ${ }^{23}$

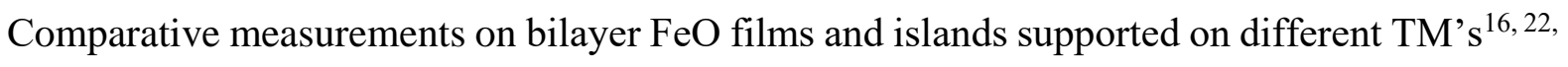
${ }^{24}$ are a facile way to gain insights into the role of the TM support. A comparison of $\mathrm{FeO}_{\text {is }} / \mathrm{Pt}(111)$ with $\mathrm{FeO}_{\text {is }} / \mathrm{Au}(111)$ is an obvious choice, because $\mathrm{Au}(111)$ is chemically inert - in contrast to $\mathrm{Pt}(111)$ - and a well-studied substrate. In fact, the $\mathrm{FeO}_{\text {is }} / \mathrm{Au}(111)$ system has been studied before, ${ }^{25,26} 16,27$ albeit to a much smaller extent than $\mathrm{FeO}_{\text {is }} / \mathrm{Pt}(111)$. Khan \& Matranga reported that $\mathrm{FeO}$ islands are formed on reconstructed $\mathrm{Au}(111)$ following the oxidation of pre-deposited $\mathrm{Fe}$ particles at RT. A moiré pattern appears on the FeO islands (see Figure 1 and Figure $\mathrm{S} 1$ in the Supporting Information), ${ }^{25}$ as known also from related systems, such as $\mathrm{FeO} / \mathrm{Pt}(111)^{28,29}$ and $\mathrm{FeO} / \mathrm{Pd}(111) \cdot{ }^{30}$ Ning et al. ${ }^{16}$ concluded that the reactive CUF sites can be best maintained under 
reaction conditions if the $\mathrm{Fe}-\mathrm{TM}$ bonding is strong, and emphasized that the $\mathrm{Fe}-\mathrm{Au}$ bonding is weaker than the Fe-Pt bonding. These authors invoke a 'confinement effect', which helps maintaining the catalytically active ensemble under reaction conditions. However, Yu et al. ${ }^{27}$ reported on a phase transition of $\mathrm{FeO}_{\text {is }} / \mathrm{Au}(111)$ under $\mathrm{CO}$ oxidation reaction conditions, with $\mathrm{Fe}_{3} \mathrm{O}_{4} / \mathrm{Au}(111)$ being the only active phase.

Here we studied the oxidation and reduction of $\mathrm{FeO}$ islands supported on $\mathrm{Au}(111)$ by highresolution STM, using $\mathrm{O}_{2}$ and $\mathrm{H}_{2}$ as oxidant and reductant, respectively. We found a very dynamic response of the $\mathrm{FeO}$ islands towards $\mathrm{O}_{2}$ and that quite a number of excess oxygen $(\mathrm{O})$ atoms can be incorporated. An STM movie obtained at RT in an $\mathrm{O}_{2}$ background revealed how further $\mathrm{O}_{2}$ dissociation events are possible after the consumption of all initially existing CUF sites. Regarding the reduction by $\mathrm{H}_{2}$, we found that $\mathrm{H}_{2}$ molecules excited through the ion gauge dissociate at the basal plane of the FeO islands. Our in situ STM results shed light onto the stability of inverse catalysts, which is a very crucial issue. Moreover, we exemplify how erroneous conclusions in $\mathrm{H}_{2}$ adsorption studies can be avoided.

\section{Results and Discussion}

We prepared the $\mathrm{FeO}$ islands in a similar way as reported previously by Khan and Matranga, ${ }^{25}$ with Fe deposition at RT onto clean $\mathrm{Au}(111)$ as the first step. This leads to the formation of Fe

islands on $\mathrm{Au}(111) .{ }^{25}$ Subsequently, we oxidized the Fe islands via a $300 \mathrm{~L}$ (Langmuir; $1 \mathrm{~L}=1 \times$ $10^{-6}$ Torr $\left.\times 1 \mathrm{~s}\right) \mathrm{O}_{2}$ exposure at $\mathrm{RT}$, followed by vacuum-annealing of the samples at $\sim 780 \mathrm{~K}$ for $10 \mathrm{~min}$. In the following, samples prepared in this way are denoted 'as-prepared $\mathrm{FeO}_{\text {is }} / \mathrm{Au}(111)$ '. 
Our high-resolution STM data of as-prepared $\mathrm{FeO}_{\text {is }} / \mathrm{Au}(111)$, presented in Figure 1, agree well with previously published results. ${ }^{16,25,27}$ The FeO islands are well-ordered and crystalline. They display a truncated-triangular shape, with a nearest neighbor distance of $3.19 \pm 0.09 \AA$. The apparent STM height of the FeO islands is $1.5 \pm 0.2 \AA\left(\mathrm{I}_{\mathrm{t}}=-0.11 \mathrm{nA} ; \mathrm{V}_{\mathrm{t}}=-370 \mathrm{mV}\right)$. At regions of locally bare $\mathrm{Au}(111)$, the well-known herringbone reconstruction ${ }^{31,32}$ can be recognized that contains alternating regions of hexagonal close packed (HCP) and face centered cubic (FCC) stacking sequences (see Figure 1a). The FeO coverage on this $\mathrm{FeO}_{\text {is }} / \mathrm{Au}(111)$ sample was $0.2 \pm$ $0.03 \mathrm{ML}$ (monolayer), whereby $1 \mathrm{ML}$ corresponds to a closed FeO film on $\mathrm{Au}(111)$.

The $\mathrm{FeO}$ islands were throughout imaged in the Fe-mode, i.e. the bright dots on the FeO islands correspond to $\mathrm{Fe}$ atoms. The clearly visible moiré pattern on the $\mathrm{FeO}$ islands arises due to the mismatch between the larger Fe-Fe mean distance in $\mathrm{FeO}(3.19 \AA)$ and the smaller lattice constant of $\mathrm{Au}(111)(2.88 \AA)$, as shown in the hard ball model in Figure S1b. The periodicity of the moiré is $30.9 \pm 0.04 \AA$.
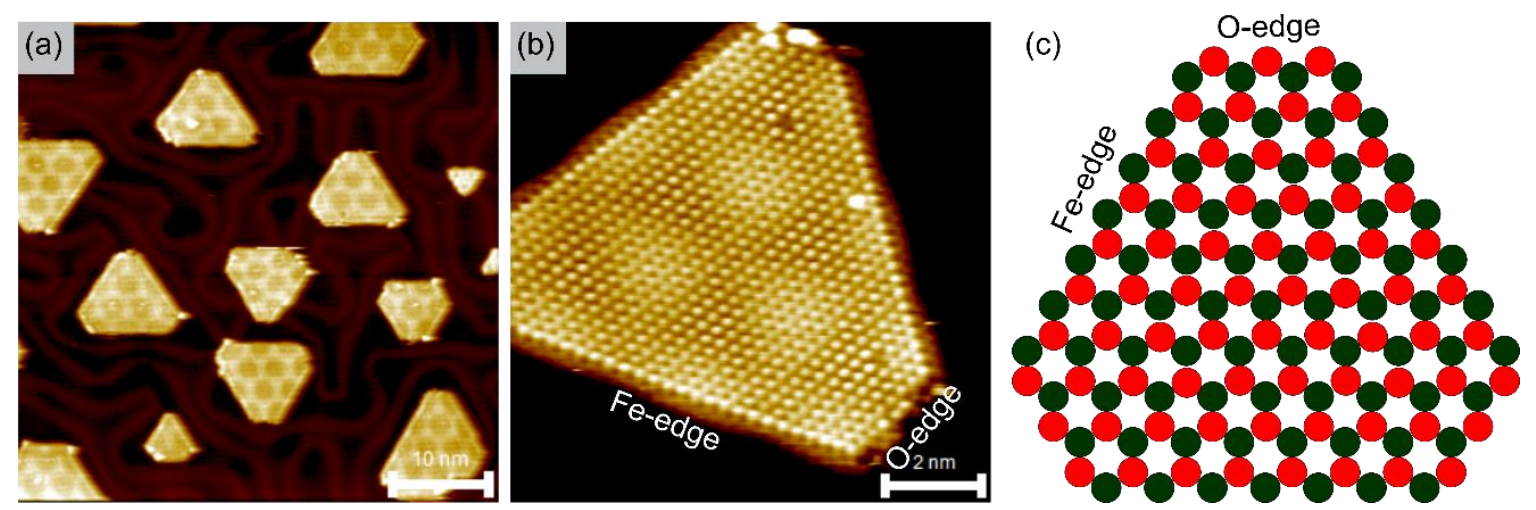

Figure 1. (a) Large-scale $\mathrm{STM}$ image $\left(500 \AA \times 500 \AA\right.$ ) of as-prepared $\mathrm{FeO}_{\text {is }} / \mathrm{Au}(111)$. (b) Atom-resolved STM image $(100 \AA \times 100 \AA)$ of a truncated triangular $\mathrm{FeO}$ island with alternating Fe-edges (the long ones) and O-edges (the short ones). (c) Ball model of an $\mathrm{FeO}$ island with $\mathrm{Fe}$ atoms shown black and $\mathrm{O}$ atoms in red. Note that the ball model shows a smaller $\mathrm{FeO}$ island than presented in (b). 
Perpendicular to the $\mathrm{Au}(111)$ substrate, the $\mathrm{FeO}$ islands are composed of an Fe layer and an $\mathrm{O}$ layer. Both these layers have hexagonal lattices and the Fe layer is sandwiched between the substrate and the $\mathrm{O}$ layer. This is the reason why closed FeO ML films are often also denoted as 'bilayers'. $7,8,28,29$ Depending on how the terminating O layer is placed with respect to the Fe layer, we distinguish between $\mathrm{FeO}$ in energetically (slightly) favored and in non-favored orientation. ${ }^{17}$ Non-favored $\mathrm{FeO}$ can be thought to be formed by shifting the $\mathrm{O}$ sub-lattice to adjacent Fe hollow sites or by rotating the favored film orientation by $60^{\circ}$. Considering the stacking order of the two topmost $\mathrm{Au}$ layers, the two $\mathrm{FeO}$ orientations are distinct. Whereas for closed $\mathrm{FeO}$ films on noble metal (111) surfaces the $\mathrm{FeO}$ occurs exclusively in one orientation (namely in the energetically slightly favored one), both $\mathrm{FeO}$ orientations occur in case of $\mathrm{FeO}$ islands. ${ }^{17}$ The fact that some of the $\mathrm{FeO}$ islands on $\mathrm{FeO}$ is / $\mathrm{Au}(111)$ are 'pointing up' and others 'pointing down' (see Figure 1a) confirm that this phenomenon ${ }^{17}$ - first observed for $\mathrm{FeO}_{\text {is }} / \mathrm{Pt}(111)$ - also occurs for $\mathrm{FeO}$ is $/$ $\mathrm{Au}(111)$. Because the ratio between $\mathrm{FeO}$ islands 'pointing up' and 'pointing down' is $\sim 1.2$ on our $\mathrm{FeO}_{\text {is }} / \mathrm{Au}(111)$ samples, we conclude that the two $\mathrm{FeO}$ orientations are energetically almost degenerated.

Because the last preparation step of $\mathrm{FeO}$ is / $\mathrm{Au}(111)$ is vacuum-annealing at high temperatures, we expect the $\mathrm{FeO}$ islands to be slightly reduced. Accordingly, the islands on as-prepared $\mathrm{FeO}_{\text {is }}$ / $\mathrm{Au}(111)$ should be characterized by Fe-terminated edges that are longer than the O-terminated edges ${ }^{17,18}$ as indicated in Figure $1 \mathrm{~b}$ and $1 \mathrm{c}$. Whereas the longer Fe-edges appear mostly perfect, the shorter O-edges are often disrupted or characterized by the presence of imperfections. That the assignment of the edges indicated in Figure 1b,c is indeed correct, is confirmed by the observed dislocation line defect structures on the $\mathrm{FeO}$ islands that are discussed below. Furthermore, this assignment is supported by the fact that Fe-edges usually appear brighter in STM images than O- 
edges, ${ }^{17}$ and by STM line profiles through the FeO-Au(111) interface (see Figure S2). Figure S2 shows a profile through the $\mathrm{FeO}-\mathrm{Au}(111)$ interface at an Fe-edge. The outermost Fe atoms (i.e. the CUF sites) are imaged with lower STM height than the Fe atoms within the basal plane. We suggest that this lower STM height of the Fe atoms at the interface originates from the lower $\mathrm{Au}-$ Fe distance that is caused by the lowered coordination to $\mathrm{O}$ atoms compared to basal plane $\mathrm{Fe}$ atoms (see Figure 1c).
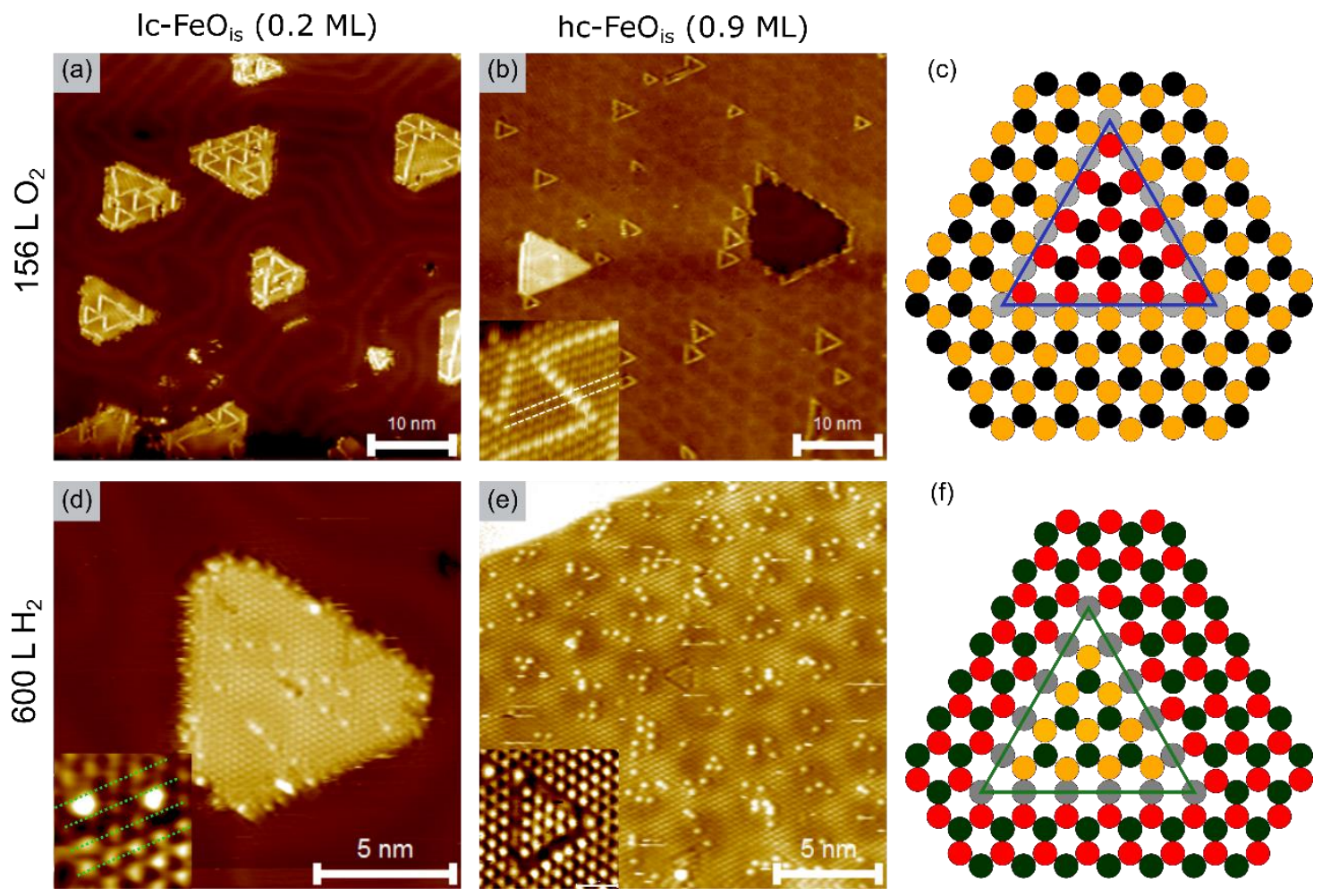

Figure 2. (a, b) STM images $(500 \AA \times 500 \AA)$ of two $\mathrm{FeO}_{\text {is }} / \mathrm{Au}(111)$ samples with 0.2 and $0.9 \mathrm{ML} \mathrm{FeO}$ island coverages that were exposed to $156 \mathrm{~L} \mathrm{O}_{2}$. On lc- $\mathrm{FeO}_{\text {is }} / \mathrm{Au}(111)$ with the low density of $\mathrm{FeO}$ islands in (a) there are more $\mathrm{O}$ adatom dislocation lines than on hc- $\mathrm{FeO}_{\text {is }} / \mathrm{Au}(111)$ (b). The inset in (b) shows an atom-resolved STM image $(38 \AA \times 38 \AA$ ) with an O adatom dislocation loop. (d, e) STM images ( $130 \AA \times 130 \AA$ and $200 \AA \times 200 \AA$, respectively) of lc-FeO is $/ \mathrm{Au}(111)$ and hc-FeO $\mathrm{Fis}_{\text {is }} / \mathrm{Au}(111)$ samples that were exposed to $600 \mathrm{~L} \mathrm{H}_{2}$. The density of hydroxyls is smallest on lc- $\mathrm{FeO}_{\text {is }} / \mathrm{Au}(111)$. The insets $(15 \AA \times 15 \AA$ and $31 \AA \times 31 \AA)$ show atom-resolved STM images (Femode) of hydroxyl groups (d) and $\mathrm{O}$ vacancy dislocations (e), respectively. (c, f) Ball models, showing how $\mathrm{O}$ atoms rearrange in $\mathrm{O}$ adatom and $\mathrm{O}$ vacancy dislocation lines. Black balls: $\mathrm{Fe}$ atoms. Red balls: $\mathrm{O}$ atoms in case of favored FeO. Yellow balls: $\mathrm{O}$ atoms in case of non-favored $\mathrm{FeO}$. The densities of $\mathrm{O}$ and $\mathrm{H}$ adatoms extracted from these experiments are given in Table 1. 
Examples for the accumulation of excess $\mathrm{O}$ adatoms on the $\mathrm{FeO}$ islands are presented in Figure 2 and the results are summarized in Table 1. We started with an as-prepared $\mathrm{FeO}_{\text {is }} / \mathrm{Au}(111)$ sample with a low FeO coverage, $\sim 0.2 \mathrm{ML}$, denoted in the following as "lc-FeOis / $\mathrm{Au}(111)$ ". Following $\mathrm{a} \sim 156 \mathrm{~L} \mathrm{O}_{2}$ exposure at $\mathrm{RT}$ to the $\mathrm{lc}-\mathrm{FeO}$ is / $\mathrm{Au}(111)$ sample, bright lines appeared on the $\mathrm{FeO}$ islands, some of which formed 'zig-zag structures' or triangular loops (Figure 2a). In analogy to the $\mathrm{FeO} / \mathrm{Pt}(111)$ and $\mathrm{FeO} / \mathrm{Pd}(111)$ systems ${ }^{17,19,30}$ we assign these line defects to $\mathrm{O}$ adatom dislocations. The $\mathrm{O}$ adatom dislocation lines appear bright in the STM images because the Fe atoms at the dislocations are four-fold coordinated (instead of three-fold coordinated as on the pristine basal plane). ${ }^{19,30}$

In a second oxidation experiment, we started with an as-prepared $\mathrm{FeO}_{\text {is }} / \mathrm{Au}(111)$ sample characterized by a high $\mathrm{FeO}$ coverage ( 0.9 ML). This high-coverage $\mathrm{FeO}_{\text {is }} / \mathrm{Au}(111)$ sample ["hc-FeO $\mathrm{O}_{\text {is }} / \mathrm{Au}(111)$ "] was likewise exposed to $\sim 156 \mathrm{~L} \mathrm{O}_{2}$ at RT, and again $\mathrm{O}$ adatom dislocation lines appeared on the $\mathrm{FeO}$ islands (Figure 2b). At this high $\mathrm{FeO}$ coverage, most $\mathrm{O}$ adatom dislocation lines appeared as triangular loops, as was previously also observed for a closed $\mathrm{FeO}$ bilayer film on $\mathrm{Pd}(111) .{ }^{30} \mathrm{Compared}$ to the $\mathrm{lc}-\mathrm{FeO}$ is / $\mathrm{Au}(111)$ sample there were clearly fewer $\mathrm{O}$ adatom dislocations lines (only $\sim 2.7 \% \mathrm{ML}$, see Table 1 ). This pronounced difference in $\mathrm{O}$ adatom coverage obtained after identical oxidation conditions suggests that the $\mathrm{FeO}-\mathrm{Au}(111)$ interface is essential for $\mathrm{O}_{2}$ dissociation, because the $\mathrm{FeO}-\mathrm{Au}(111)$ interface is clearly larger on $1 \mathrm{c}-\mathrm{FeO}$ is / $\mathrm{Au}(111)$ than on hc-FeOis / $\mathrm{Au}(111)$. More specifically, we assess that the CUF sites are the active sites for $\mathrm{O}_{2}$ dissociation, as is also the case for $\mathrm{FeO}_{\text {is }} / \mathrm{Pt}(111){ }^{5,12,18}$

In another set of experiments, we reduced two as-prepared $\mathrm{FeO}_{\text {is }} / \mathrm{Au}(111)$ samples with 600 $\mathrm{L} \mathrm{H}_{2}$ exposure at $\mathrm{RT}$. Because the $\mathrm{FeO}$ coverages were identical to those in the oxidation experiments, the two samples are also denoted lc- $\mathrm{FeO}_{\text {is }} / \mathrm{Au}(111)$ and hc-FeO is / $\mathrm{Au}(111)$, 
respectively. As the result of the $\mathrm{H}_{2}$ exposures we observed two different features: (i) bright pointlike defects, and (ii) a few triangular extended defects (Figure 2d,e). On the basis of previous studies, we can assign these features to hydroxyl groups (that is $\mathrm{H}$ adatoms) $)^{19,33}$ and $\mathrm{O}$ vacancy dislocation loops, ${ }^{17,34,35}$ respectively. Because only few $\mathrm{O}$ vacancy dislocation loops appeared in these experiments, we focus in the following exclusively on the $\mathrm{H}$ adatoms. On hc-FeO is / $\mathrm{Au}(111)$, the density of $\mathrm{H}$ adatoms was higher than on $\mathrm{lc}-\mathrm{FeO}_{\text {is }} / \mathrm{Au}(111)$, see Table 1, even though the total length of Fe-edges (i.e. the number of CUF sites) was largest on lc-FeO is / $\mathrm{Au}(111)$. Accordingly, the $\mathrm{FeO}-\mathrm{Au}(111)$ interface does not host the active sites for $\mathrm{H}_{2}$ dissociation over $\mathrm{FeO}_{\text {is }} / \mathrm{Au}(111)$. Instead, our results are consistent with the basal plane of the $\mathrm{FeO}$ islands being active for $\mathrm{H}_{2}$ adsorption and dissociation. Below we argue that the $\mathrm{H}_{2}$ molecules need to be vibrationally excited to make their dissociation over $\mathrm{FeO} / \mathrm{Au}(111)$ possible and that the ion gauge is sufficient to induce such excitations.

\begin{tabular}{|c|c|c|}
\hline sample & ${\mathrm{lc}-\mathrm{FeO}_{\text {is }}}$ & $\mathrm{hc}-\mathrm{FeO}_{\text {is }}$ \\
\hline FeO coverage (ML) & 0.2 & 0.9 \\
\hline $\begin{array}{c}\text { O adatom density (\%) on } \mathrm{FeO} \\
\text { following a 156 } \mathrm{L} \mathrm{O}_{2} \text { exposure }\end{array}$ & 14.0 & 2.7 \\
\hline $\begin{array}{c}\mathrm{H} \text { adatom density on } \mathrm{FeO}\left(\mathrm{nm}^{-1}\right) \\
\text { following a 600 } \mathrm{L} \mathrm{H}_{2} \text { exposure }\end{array}$ & 0.35 & 0.70 \\
\hline
\end{tabular}

Table 1. Results of the quantitative analysis corresponding to the STM experiments presented in Figure 2. 


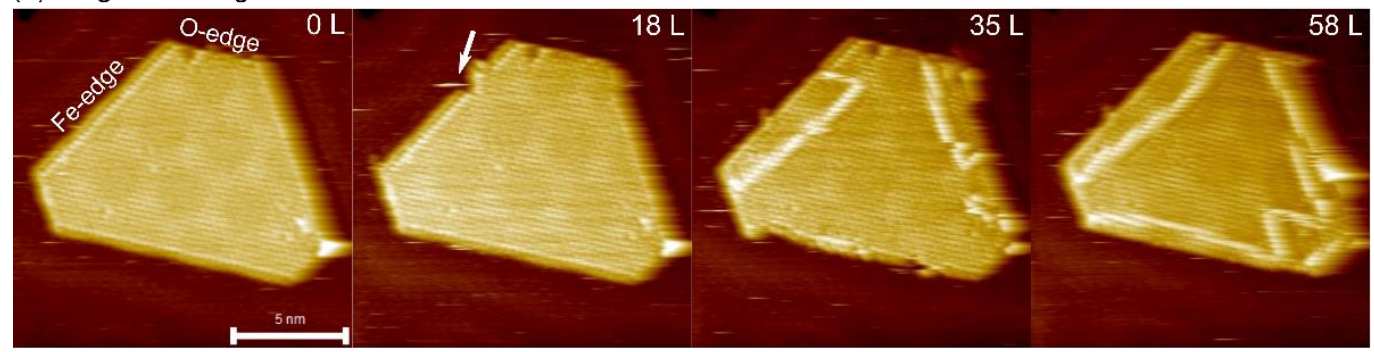

(b) Stage II: Fe-edges dynamically exposed

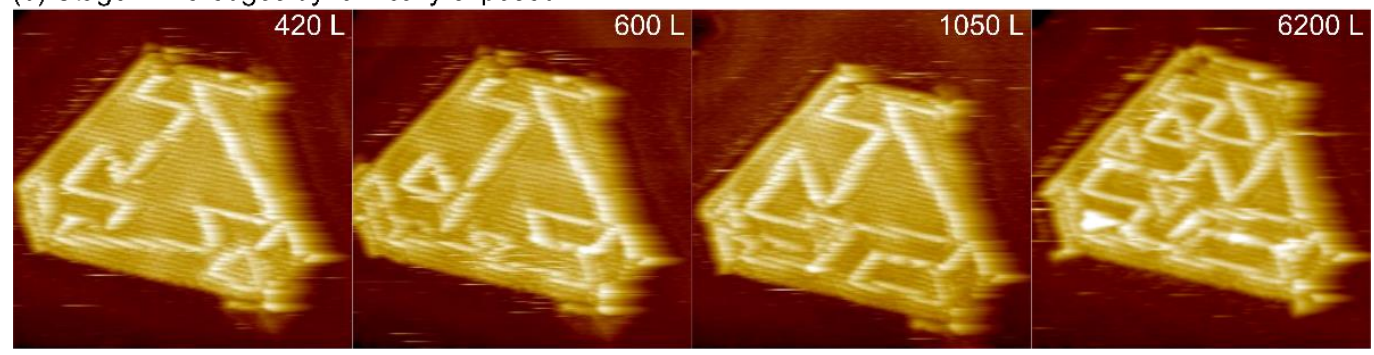

(c)
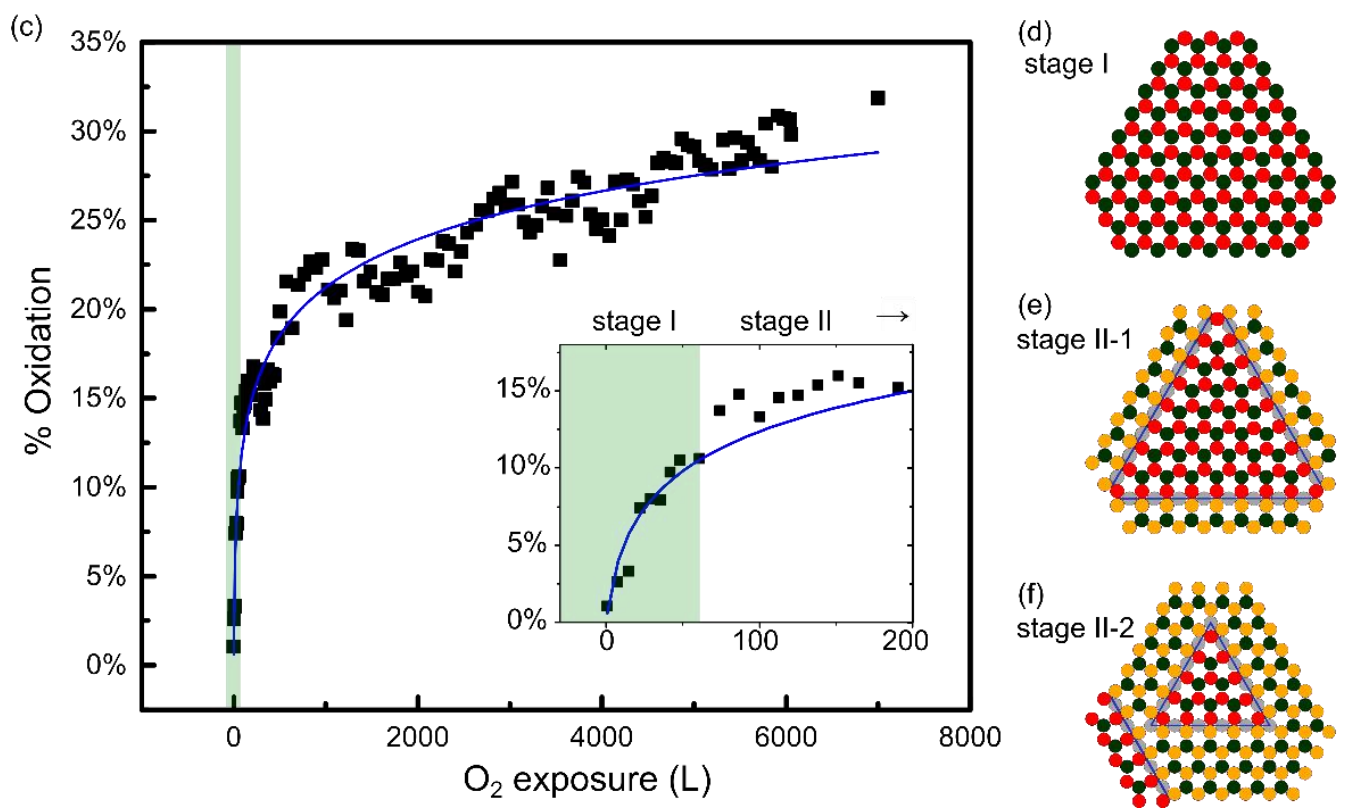

Figure 3. (a, b) Sequence of atom-resolved images $(150 \AA \times 150 \AA)$ selected from STM movie "M1_O adatom defects" (see Supporting Information) that was recorded on a lc-FeO $\mathrm{is}_{\mathrm{s}} / \mathrm{Au}(111)$ sample during $\mathrm{O}_{2}$ exposure $(\sim 7.9 \times$ $10^{-7}$ Torr) at RT. The focus is on one typical FeO island on this sample. (a) Initial stage of oxidation characterized by direct access to Fe-edges $(0-58 \mathrm{~L})$. (b) Second stage of oxidation without direct access to Fe-edges $(58-6200 \mathrm{~L})$. (c) Plot of $\mathrm{O}$ adatom coverage (\% oxidation) versus $\mathrm{O}_{2}$ exposure. Initially, the coverage of $\mathrm{O}$ adatom dislocation lines increase very strongly (stage I). In stage II, the increase is much smaller than in stage I. The blue curve is a fit, using a logarithmic approach. The inset shows the transition between stage I and II oxidation enlarged. (d-f) Simplified ball models (color-coding as used above) of the FeO island, illustrating how the two oxidation stages can be explained at the atomic scale. For the sake of simplicity, the models are drawn smaller than the FeO island observed experimentally. 
From the STM data presented in Figure 2, it follows that: (i) The identification of the long edges of the $\mathrm{FeO}$ islands as Fe-edges is correct. The orientation of the observed dislocation line defects (both types) shows this. ${ }^{17}$ (ii) More importantly, the adsorption sites of $\mathrm{H}_{2}$ and $\mathrm{O}_{2}$ must be different from each other. For $\mathrm{O}_{2}$ dissociation reactions, the CUF sites are essential, i.e., the $\mathrm{FeO}-$ $\mathrm{Au}(111)$ interface. In contrast, for $\mathrm{H}_{2}$ dissociation reactions, the basal planes of the $\mathrm{FeO}$ islands provide the active sites for $\mathrm{H}_{2}$ adsorption and dissociation.

In what follows, we shed light onto the question how the $\mathrm{O}$ adatom dislocation line defects are created on the $\mathrm{FeO}_{\text {is }} / \mathrm{Au}(111)$ samples. To do so, we recorded several STM movies on an asprepared $\mathrm{FeO}$ is / $\mathrm{Au}(111)$ sample in an $\mathrm{O}_{2}$ background (as an example, see Figure 3 and movie "M1_O adatom defects" in the Supporting Information). The selected STM movie was recorded in $\sim 7.9 \times 10^{-7}$ Torr $\mathrm{O}_{2}$ and focuses on the evolution of one single, representative $\mathrm{FeO}$ island of a lc- $\mathrm{FeO}_{\text {is }} / \mathrm{Au}(111)$ sample. At the beginning of the STM movie, the $\mathrm{FeO}$ island was dominated by three long Fe-edges [see Figure 3a (0 L) and Figure 3d]. At $\sim 18 \mathrm{~L} \mathrm{O}_{2}$ exposure [Figure 3a (18 L)] the first indication of oxidation appeared: the formation of a kink at the Fe-edge on the left (marked by a white arrow). Next, two $\mathrm{O}$ adatom dislocation lines appeared at $\sim 35 \mathrm{~L} \mathrm{O}_{2}$ exposure, running parallel and close to edges that originally were Fe-edges, thereby transforming the Fe-edges into O-edges [Figure $3 \mathrm{a}(35 \mathrm{~L})$ ]. At a total $\mathrm{O}_{2}$ exposure of $\sim 58 \mathrm{~L}$, all original Fe-edges had transferred into O-edges. As shown previously, ${ }^{17}$ this implies that the $\mathrm{FeO}$ in the ribbons parallel to the three long edges inverted to the other $\mathrm{FeO}$ orientation compared to the $\mathrm{FeO}$ in the center of the island (see Figure 3e). The interval between 0 and $\sim 58 \mathrm{~L} \mathrm{O}_{2}$ exposures (denoted "stage I oxidation" of the $\mathrm{FeO}$ island) is characterized by the presence of Fe-edges at the $\mathrm{FeO}-\mathrm{Au}(111)$ interface.

Upon further $\mathrm{O}_{2}$ exposure [Figure $3 \mathrm{~b}(58-6200 \mathrm{~L})$ ], denoted "stage II", the $\mathrm{FeO}$ island underwent additional transformations. In the course of these transformations, more $\mathrm{O}$ adatoms 
were incorporated into the $\mathrm{FeO}$ island, even though it seems, at first glance, that there were no CUF sites available. Comparing the situations at $58 \mathrm{~L}$ and at $420 \mathrm{~L} \mathrm{O}_{2}$ exposure, the coverage of $\mathrm{O}$ adatom dislocations clearly became larger. Accordingly, at $420 \mathrm{~L} \mathrm{O}_{2}$ exposure, the FeO island showed many more inversions from one to the other $\mathrm{FeO}$ orientation than was the case at $58 \mathrm{~L} \mathrm{O}_{2}$ exposure. In addition, 'zig-zag'-shaped $\mathrm{O}$ adatom dislocation lines and closed triangular $\mathrm{O}$ adatom dislocation loops appeared after $420 \mathrm{~L} \mathrm{O}_{2}$ exposure, and more of such line defects appeared at even higher $\mathrm{O}_{2}$ exposure (see Figure $3 \mathrm{~b}$ ). Thus, excessive $\mathrm{O}_{2}$ exposure at $\mathrm{RT}$ led to a 'rag rug' of $\mathrm{FeO}$ with alternating $\mathrm{FeO}$ orientations. In this way, all the edges became O-edges, even though the overall shape of the $\mathrm{FeO}$ island remained the same. The situation of the $\mathrm{FeO}$ island during stage II oxidation is schematically shown in Figure 3e,f.

We conducted a quantitative analysis of the STM movie "M1_O adatom defects" to disclose the difference between stage I and stage II oxidation. In Figure 3c, each dot represents an STM image that was recorded within the movie, and the oxidation degree $(\%$ oxidation $=\mathrm{O}$ adatom coverage) of the $\mathrm{FeO}$ island is shown as function of $\mathrm{O}_{2}$ exposure (notice that only selected STM images were analyzed). During initial oxidation (stage I), the oxidation degree increased strongly, as can be seen from the steep slope of the curve fit (blue, solid line). Between $\sim 60$ and $\sim 3500 \mathrm{~L}$ $\mathrm{O}_{2}$ exposure (part 1 of stage II), a transition occurred to a much slower increase of the oxidation degree, and for $\mathrm{O}_{2}$ exposures greater than $\sim 3500 \mathrm{~L}$ (part 2 of stage II), the oxidation degree increased nearly linearly at a relatively low rate. It seems that even at a total of $\sim 7500 \mathrm{~L} \mathrm{O}_{2}$ exposure, complete saturation of the oxidation degree was not reached yet.

To interpret the data presented in Figure 3 we anticipate that the CUF sites are the only active sites for $\mathrm{O}_{2}$ dissociation. During stage I oxidation, the CUF sites are easily accessible. Hence, $\mathrm{O}_{2}$ dissociation reactions and the incorporation of $\mathrm{O}$ adatoms into the $\mathrm{FeO}$ islands are very facile. At 
the beginning of stage II oxidation (part 1), the formation of additional $\mathrm{O}$ adatom dislocation lines slowed down because all original CUF sites were already consumed during stage I oxidation. Why does the oxidation of $\mathrm{FeO}$ islands not stop at this stage? We propose that new CUF sites are created upon the formation of $\mathrm{O}$ adatom dislocations, i.e. when the $\mathrm{FeO}$ islands rearrange, or that the same CUF sites can be used multiple times for $\mathrm{O}_{2}$ dissociation due to the rearrangement of the $\mathrm{O}$ atoms within the islands. During part 1 of stage II oxidation, such rearrangements (O diffusion events) are quite facile. However, for $\mathrm{O}_{2}$ exposures greater than $\sim 3500 \mathrm{~L}$ it appears that the rearrangement of the $\mathrm{O}$ atoms within the $\mathrm{FeO}$ islands becomes energetically more costly, so that new CUF sites can only be created at a very low rate. In addition, more $\mathrm{O}$ atoms need to diffuse to free another CUF site, the higher the oxidation state of the island. These two factors may explain why the rate of $\mathrm{O}$ adatom incorporation slows down further for high $\mathrm{O}_{2}$ exposures.

Compared to the high density of $\mathrm{O}$ adatom dislocation line defects found here, the reported data for $\mathrm{FeO}$ bilayers on $\mathrm{Pt}(111)$ and $\mathrm{Pd}(111)$ substrates show much lower densities. ${ }^{17-20,30}$ For example, on $\mathrm{Pt}(111)$-supported $\mathrm{FeO}$ islands, only very few $\mathrm{O}$ dislocation lines were found following $\mathrm{O}_{2}$ exposure for $60 \mathrm{~min}$ at $10^{-8} \operatorname{Torr}(\sim 48 \mathrm{~L}) \cdot{ }^{20}$ Furthermore, on $\operatorname{Pt}(111)$ and $\operatorname{Pd}(111)$ substrates, the formation of $\mathrm{O}$ adatom dislocations was mostly observed if the samples were oxidized at elevated temperatures $(>400 \mathrm{~K})$, and in most cases it was not possible to avoid the simultaneous formation of $\mathrm{O}-\mathrm{Fe}-\mathrm{O}$ trilayer islands on the $\mathrm{FeO}$ islands and $\mathrm{FeO}$ films.${ }^{19} \mathrm{We}$ explain the high density of $\mathrm{O}$ adatom dislocation lines on $\mathrm{FeO}_{\text {is }} / \mathrm{Au}(111)$ by the low adhesion of the $\mathrm{FeO}$ island on $\mathrm{Au}(111)^{16,22}$ and the fact that the formation of $\mathrm{O}-\mathrm{Fe}-\mathrm{O}$ trilayer islands on $\mathrm{FeO}$ is / $\mathrm{Au}(111)$ is not pronounced at RT (see Figure S3).

On the basis of this comparison, we agree with previous reports ${ }^{5,12,16,20}$ that a strong Fe-TM bonding is advantageous for maintaining the catalytic activity under reaction conditions. However, 13 
the revealed highly dynamic behavior of the $\mathrm{FeO}$ islands with regard to $\mathrm{O}_{2}$ indicates that the 'lifetime' of the CUF sites is limited at oxidizing conditions. Here we have shown this for $\mathrm{FeO}_{\text {is }} /$ $\mathrm{Au}(111)$, but it is likewise the case for $\mathrm{FeO}$ is / $\mathrm{Pt}(111)$, as shown previously. ${ }^{15,17}$ Accordingly, the catalytically active CUF sites need to be regenerated at realistic reaction conditions. Thus, the concept of 'interface confinement' might casually be misleading, as it implies that the active ensemble (and the active sites) were maintained under reaction conditions. However, for evaluating whether a specific $\mathrm{FeO} / \mathrm{TM}$ inverse system is relevant in a catalyzed reaction, the critical question is whether the proposed active centers can be recreated (or replenished) at reaction conditions rather than maintained. Indeed, for $\mathrm{FeO}_{\text {is }} / \mathrm{Pt}(111)$, it has been reported that the presence of $\mathrm{H}_{2}$ in the reaction gas stream is critical to keep the $\mathrm{CO}$ oxidation activity high, which otherwise decreases quickly. ${ }^{15}$

Having created $\mathrm{FeO}_{\text {is }} / \mathrm{Au}(111)$ samples with a high density of $\mathrm{O}$ adatom dislocation lines, we also studied whether the $\mathrm{O}$ adatom dislocations can be removed through reduction by $\mathrm{H}_{2}$ (see Figure 4 and STM movie "M2_H2 exposure" in the Supporting Information). Figure 4a shows six selected cutouts of the STM movie "M2_H2 exposure", which was recorded in $\sim 5.2 \times 10^{-6}$ Torr $\mathrm{H}_{2}$ at $\mathrm{RT}$. We focus on an area that showed an Fe-edge before the oxidation of the sample (see STM movie "M3_O2 exposure" in the Supporting Information). Upon oxidation by $\sim 60 \mathrm{~L} \mathrm{O}_{2}$ at RT, this Fe-edge was transferred into an O-edge and the bright, triangular / 'zig-zag'-shaped O adatom dislocation lines - appeared (see the discussion above). Movie "M2_H2 exposure" shows that the $\mathrm{O}$ adatom dislocation lines shrink upon $\mathrm{H}_{2}$ exposure, and finally disappear at a total $\mathrm{H}_{2}$ exposure of $\sim 11 \times 10^{3} \mathrm{~L}$. It can also be seen in the STM movie that the $\mathrm{O}$ adatom dislocation lines are flipping forth and back between slightly different configurations during STM imaging when the ion gauge was off. However, without excitation of $\mathrm{H}_{2}$ through the ion gauge, the $\mathrm{O}$ adatom 
dislocations did not shrink. In Figure 4a, the status of the ion gauge in the ultra-high vacuum (UHV) chamber is given in each STM image in the upper right corner.
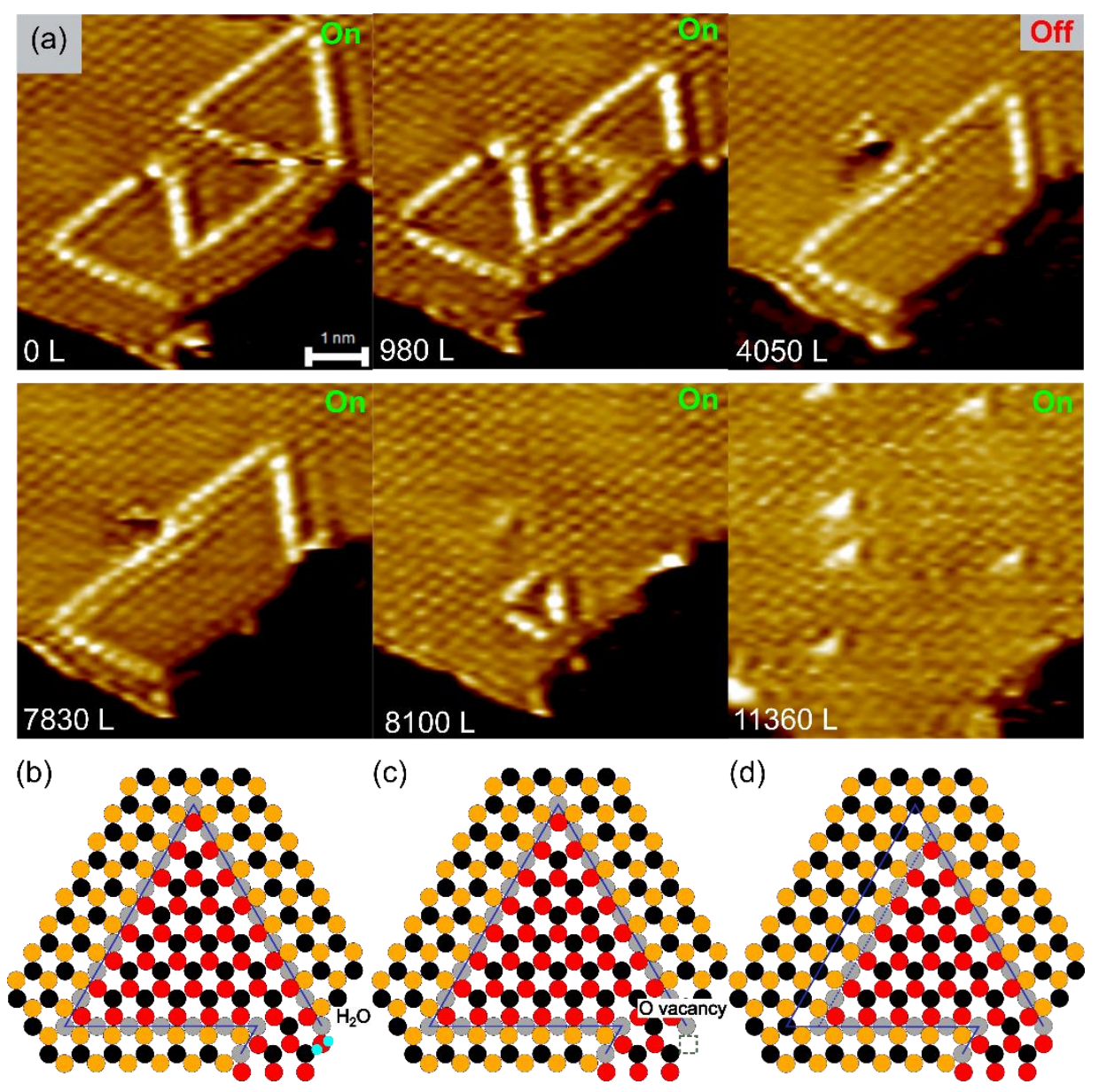

Figure 4. (a) Selected atom-resolved STM images recorded during $\mathrm{H}_{2}$ exposure $\left(\sim 5.2 \times 10^{-6}\right.$ Torr $)$ at RT within movie "M2_H2 exposure" (see Supporting Information). Starting point was an oxidized $\mathrm{FeO}_{\text {is }} / \mathrm{Au}(111)$ sample that was created using $\sim 60 \mathrm{~L} \mathrm{O}_{2}$ at RT (see STM movie "M3_O2 exposure" in the Supporting Information). With the ion gauge operating, removal of $\mathrm{O}$ adatom dislocation lines ( $\mathrm{O}$ adatoms) is observed. In each STM image, the state of the ion gauge (on or off) as well as the total $\mathrm{H}_{2}$ exposure is indicated. (b-d) Sequence of $\mathrm{FeO}$ model islands (color-coding as used above), illustrating how $\mathrm{O}$ adatoms can be removed from an $\mathrm{FeO}$ island, leading to the shrinking of $\mathrm{O}$ adatom dislocation lines on the island. Notice the water molecule in (b) and the transient $\mathrm{O}$ vacancy in (c). 
The surprising influence of the ion gauge is further documented in Figure 5a, where the oxidation degree of the studied $\mathrm{FeO}$ island is plotted as function of the $\mathrm{H}_{2}$ exposure. The $\mathrm{FeO}$ island was exclusively reduced by the $\mathrm{H}_{2}$ during times where the ion gauge was switched on. If the ion gauge was off (see the marked exposure range in the middle of Figure 5a), there was no reduction at all.

As seen in the last two selected cutouts of STM movie "M2_H2 exposure" in Figure 4a, the O adatom dislocation lines can be completely removed from the $\mathrm{FeO}$ island through $\mathrm{H}_{2}$ exposure, supposed the ion gauge is operating. In addition, new bright point defects appeared on the $\mathrm{FeO}$ island at $\sim 11360 \mathrm{~L} \mathrm{H}_{2}$. These point defects are assigned to $\mathrm{H}$ adatoms (compare to Figure 2d,e).
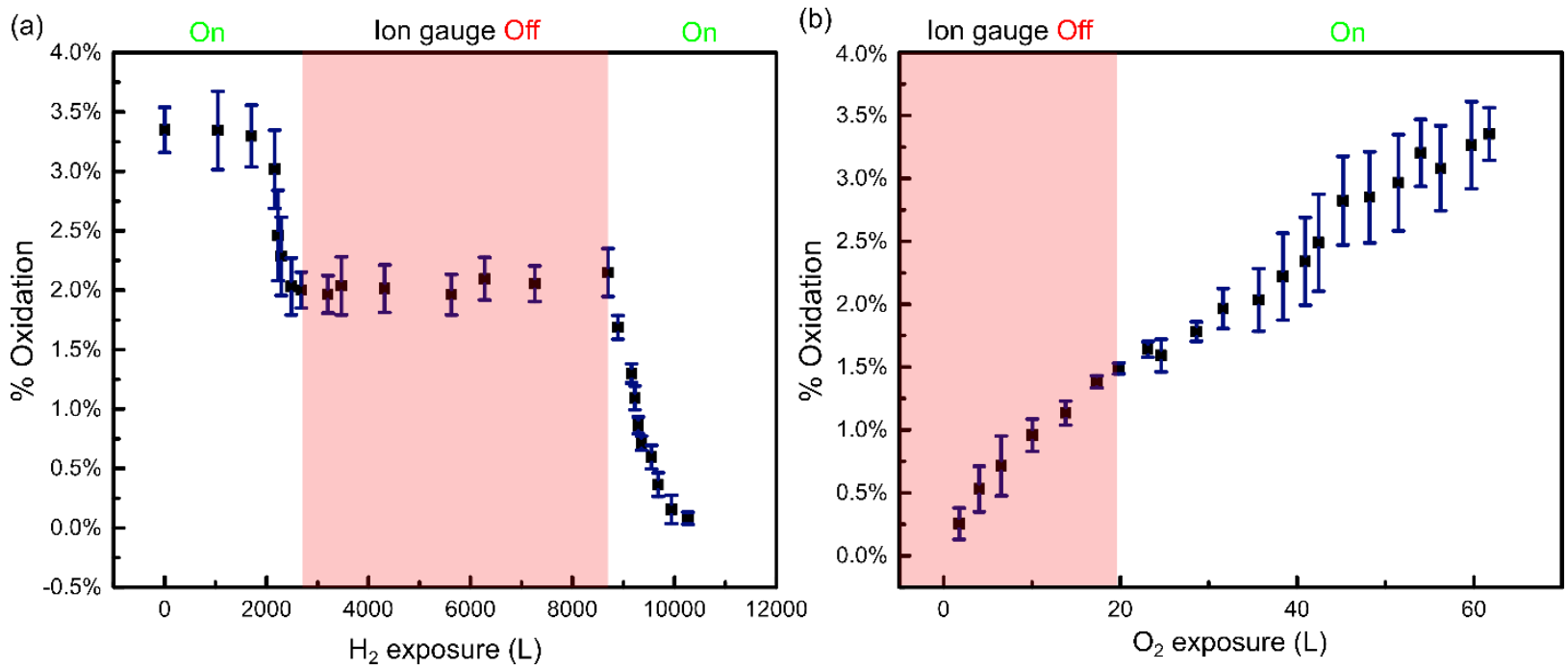

Figure 5. (a) Plot of the oxidation degree versus $\mathrm{H}_{2}$ exposure with the ion gauge either on (intervals on the left and right) or off (interval in the middle marked by color). The data were extracted from the STM movie "M2_H2 exposure" (see Figure 4 and Supporting Information). A decrease of $\mathrm{O}$ adatom dislocation lines (expressed as \% oxidation) was only observed when the ion gauge was operating. (b) Plot of the degree of oxidation versus $\mathrm{O}_{2}$ exposure with the ion gauge either off (left side) or on (right side). The data were extracted from the STM movie "M3_O2 exposure" (see Supporting Information). Here, the results are not affected by the ion gauge. 
The fact that reduction of the $\mathrm{FeO}$ islands upon $\mathrm{H}_{2}$ exposure exclusively occurred when the ion gauge was operating lets us conclude that a part of the $\mathrm{H}_{2}$ molecules are vibrationally excited through the ion gauge, ${ }^{36}$ and that only these vibrationally excited $\mathrm{H}_{2}$ molecules dissociate over $\mathrm{FeO} / \mathrm{Au}(111)$. As shown previously, such vibrationally excited $\mathrm{H}_{2}$ molecules are produced via Eley-Rideal abstraction reactions between gas-phase $\mathrm{H}$ atoms and $\mathrm{H}$ atoms adsorbed on metal surfaces. ${ }^{37,}{ }^{38} \mathrm{H}_{2}$ molecules excited this way exhibit superthermal vibrational energy level populations up to at least $v=9 \cdot{ }^{37,38}$ The gaseous $\mathrm{H}$ atoms, that are also produced by hot filaments in the chamber, are unlikely the source of the reduction reaction observed here, because the $\mathrm{FeO}_{\text {is }}$ / $\mathrm{Au}(111)$ sample was well protected from them in the STM instrument. Note that gaseous $\mathrm{H}$ atoms are known to either adsorb or undergo abstraction reactions upon collision with metal surfaces. However, vibrationally excited $\mathrm{H}_{2}$ molecules can survive hundreds of collisions before they thermalize. ${ }^{37}$ Thus, vibrationally excited $\mathrm{H}_{2}$ molecules can reach the $\mathrm{FeO}$ is / $\mathrm{Au}(111)$ surface and eventually dissociate even though the sample was placed in the STM instrument.

Because of the high dissociation energy of $\mathrm{H}_{2}$ molecules $(432 \mathrm{~kJ} / \mathrm{mol})$ it is generally difficult to dissociate $\mathrm{H}_{2}$ molecules. Thus, it is surprising that vibrationally excited $\mathrm{H}_{2}$ molecules dissociate on the $\mathrm{FeO}_{\text {is }} / \mathrm{Au}(111)$ surface. The barrier for $\mathrm{H}_{2}$ dissociation must be lower on $\mathrm{FeO}_{\text {is }} / \mathrm{Au}(111)$ than on other iron oxide systems ${ }^{15,35,39,40}$ that were found to be inert towards $\mathrm{H}_{2}$ under UHV conditions (with the ion gauge operating). Regarding $\mathrm{FeO} / \mathrm{Pt}(111)$ and $\mathrm{FeO}$ is / $\mathrm{Pt}(111)$, notice that either atomic hydrogen has to be used for reduction at $\mathrm{RT}^{35,40}$ or $\mathrm{H}_{2}$ pressures in the mbar range. ${ }^{15}$ We surmise that the mechanism at play on $\mathrm{FeO}_{\text {is }} / \mathrm{Au}(111)$ is similar to the one predicted for ultrathin $\mathrm{MgO}$ films supported on $\mathrm{Au}(001)$, where electron tunneling through the oxide film is possible because of the large work function of $\mathrm{MgO} / \mathrm{Au}(001) .{ }^{41}$ In the mechanism predicted for 
$\mathrm{MgO} / \mathrm{Au}(001)$, two $\mathrm{OH}$ groups are formed for each $\mathrm{H}_{2}$ molecule that undergoes dissociation (homolytic $\mathrm{H}_{2}$ dissociation).

How do the $\mathrm{O}$ adatom dislocation lines shrink through the interaction with vibrationally excited $\mathrm{H}_{2}$ molecules? In Figures $4 \mathrm{~b}-\mathrm{d}$ we propose a possible atomistic mechanism for this process. $\mathrm{O}$ adatoms in the proximity to the $\mathrm{FeO}-\mathrm{Au}(111)$ interface recombine with $\mathrm{H}$ adatoms, forming water molecules that desorb immediately after their creation. In this way, $\mathrm{O}$ vacancies are created at the $\mathrm{FeO}-\mathrm{Au}(111)$ interface. Because we did not observe any structures with $\mathrm{O}$ vacancies within our STM movies, such structures must be transient at RT. The $\mathrm{O}$ vacancies are probably healed quickly through $\mathrm{O}$ adatoms diffusion events, leading to the formation of more stable structures of shorter $\mathrm{O}$ adatom dislocation lines and different areas of original and inverted $\mathrm{FeO}$ patches, as observed in the STM movie. Our proposal that the $\mathrm{FeO}-\mathrm{Au}(111)$ interface is involved in the reduction process via water desorption and $\mathrm{O}$ vacancy formation is consistent with previous studies addressing the interactions of water with $\mathrm{FeO}_{\text {is }} / \mathrm{Au}(111)^{26}$ and $\mathrm{CoO}_{\text {is }} / \mathrm{Au}(111),{ }^{42}$ respectively. These studies revealed that water dissociates exclusively at the FeO-TM interface, and not at the basal planes of the $\mathrm{FeO}$ islands.

Because the reduction of the $\mathrm{FeO}$ islands via $\mathrm{H}_{2}$ is strongly affected by the ion gauge, we checked whether the status of the ion gauge (on or off) also influences the processes occurring upon $\mathrm{O}_{2}$ exposure (Figure $5 b$ ). However, we did not find any sign that the oxidation processes is altered through the ion gauge.

On the basis of our $\mathrm{H}_{2}-\mathrm{FeO}$ is / $\mathrm{Au}(111)$ studies and recent work by Kyhl et al. ${ }^{36}$ we conclude that special care has to be taken in $\mathrm{H}_{2}$ adsorption studies. Because the use of ion gauges is standard in UHV chambers, vibrationally excited $\mathrm{H}_{2}$ rather than thermalized $\mathrm{H}_{2}$ molecules may previously 
in some cases have been the cause of observed $\mathrm{H}_{2}$ dissociation events. For future $\mathrm{H}_{2}$ adsorption studies, we propose the conduction of control experiments that allow one to clearly exclude any alteration of the experimental conditions due to hot filaments. The conduction of such control experiments is straightforward, as shown here for $\mathrm{H}_{2}-\mathrm{FeO}$ is / $\mathrm{Au}(111)$ as an example.

In addition to this important technical point, our $\mathrm{H}_{2}-\mathrm{FeO}$ is / $\mathrm{Au}(111)$ studies show that reduction via molecular hydrogen might be a possible way to remove excess $\mathrm{O}$ adatoms from the $\mathrm{FeO}_{\text {is }} / \mathrm{Au}(111)$ sample. The essential point is the creation of $\mathrm{H}$ adatoms, which subsequently can reduce the $\mathrm{FeO}_{\text {is }} / \mathrm{Au}(111)$ samples via water formation and desorption. The barrier for $\mathrm{H}_{2}$ dissociation over $\mathrm{FeO}_{\text {is }} / \mathrm{Au}(111)$ must be lower than that for $\mathrm{FeO}_{\text {is }} / \mathrm{Pt}(111)$, because thermally activated $\mathrm{H}_{2}$ molecules dissociate in $\mathrm{UHV}$ exclusively on $\mathrm{FeO}$ is / $\mathrm{Au}(111)$. The reduction of inverse catalysts, such as the $\mathrm{FeO}_{\text {is }} / \mathrm{Au}(111)$ model catalyst considered here, is of great relevance to replenish the catalytically relevant sites.

\section{Conclusions}

Using in situ STM, we studied the oxidation and reduction of $\mathrm{Au}(111)$-supported $\mathrm{FeO}$ bilayer islands. We found an astonishing dynamic behavior of the $\mathrm{FeO}$ islands upon oxidation by $\mathrm{O}_{2}$, leading to an incorporation of excess $\mathrm{O}$ atoms into the islands, in the form of $\mathrm{O}$ adatom dislocation line defects. For $\mathrm{O}_{2}$ dissociation reactions, the Fe-edges at the $\mathrm{FeO}-\mathrm{Au}(111)$ interface (i.e., the CUF sites) are essential, as in the case of $\mathrm{FeO}_{\text {is }} / \mathrm{Pt}(111)$. After the consumption of all initially existing CUF sites on $\mathrm{FeO}_{\text {is }} / \mathrm{Au}(111)$, further $\mathrm{O}_{2}$ dissociation events are possible through the creation of new CUF sites, leading to oxidized $\mathrm{FeO}$ islands. In contrast to this, the CUF sites are not relevant for $\mathrm{H}_{2}$ dissociation over $\mathrm{FeO}_{\text {is }} / \mathrm{Au}(111)$. We found that $\mathrm{H}_{2}$ molecules that were 
vibrationally excited through the ion gauge dissociate at the basal plane of the $\mathrm{FeO}$ islands. However, the $\mathrm{FeO}-\mathrm{Au}(111)$ interface still plays a role within the reduction reaction, because the reduction through $\mathrm{H}_{2}$ occurs most likely via water formation, and the water molecules may desorb from the $\mathrm{FeO}-\mathrm{Au}(111)$ interface.

Our STM results uncover the highly dynamic nature of inverse catalysts, which is closely connected to their stability (or instability) under reaction conditions. Rather than thinking in terms of maintaining the catalytically active ensemble, the presented data underline that it is crucial to consider whether the proposed active centers can be replenished during a catalyzed reaction.

Regarding our $\mathrm{H}_{2}$ adsorption studies, we discovered that vibrationally excited $\mathrm{H}_{2}$ molecules rather than thermalized $\mathrm{H}_{2}$ can reach and react with the sample surface during STM imaging. Accordingly, special care needs to be taken in $\mathrm{H}_{2}$ adsorption studies in order to avoid any alteration of the experimental conditions due to hot filaments.

\section{Methods}

All STM measurements were performed at RT using a home-built Aarhus STM, ${ }^{43,44}$ in an UHV chamber with a base pressure of $\sim 8 \times 10^{-11} \mathrm{Torr}^{35,45} \mathrm{The} \mathrm{FeO}$ is $/ \mathrm{Au}(111)$ samples were imaged in constant current mode using mechanically cut Pt/Ir tips. Scanning parameters were typically $\mathrm{I}_{t}=$ $[-0.12 ;-0.3] \mathrm{nA}$ and $\mathrm{V}_{\mathrm{t}}=[-55 ;-130] \mathrm{mV}$. Because the scanner tube was particularly short, very stable and fast scanning was possible with high resolution. The sample temperature was measured by a K-type thermocouple spot-welded to the back of the $\mathrm{Au}(111)$ crystal. $\mathrm{O}_{2}$ and $\mathrm{H}_{2}$ gases were introduced into the UHV chamber through separate leak valves. The given exposures during STM 
imaging are overestimated, because the gas pressures were measured in the UHV chamber and not in the tunnel junction.

The $\mathrm{Au}(111)$ sample was cleaned by cycles of $\mathrm{Ar}^{+}$sputtering $\left(\mathrm{p}=6 \times 10^{-5} \mathrm{Torr}, 2 \mathrm{keV}\right)$ at $\mathrm{RT}$ and annealing at $\sim 800 \mathrm{~K}$ for $15 \mathrm{~min}$. Sample cleanliness was checked by atom-resolved STM imaging. The $\mathrm{FeO}$ islands were prepared in a similar way as reported by Khan and Matranga. ${ }^{25}$ First, Fe was deposited from an Fe rod (Goodfellow, 99.99\%, d $\sim 2.5 \mathrm{~mm}$ ) onto clean $\mathrm{Au}(111)$ at RT via an electron-beam evaporator (EGCO4, Oxford Applied Research). Subsequently, $\mathrm{O}_{2}$ was introduced into the chamber at RT with a pressure of $1 \times 10^{-6}$ Torr for $5 \mathrm{~min}$. Following this oxidation step, the samples were annealed at $\sim 780 \mathrm{~K}$ for $10 \mathrm{~min}$ in UHV. The coverage of the FeO islands was adjusted between 0.14 and $0.9 \mathrm{ML}$.

TOC

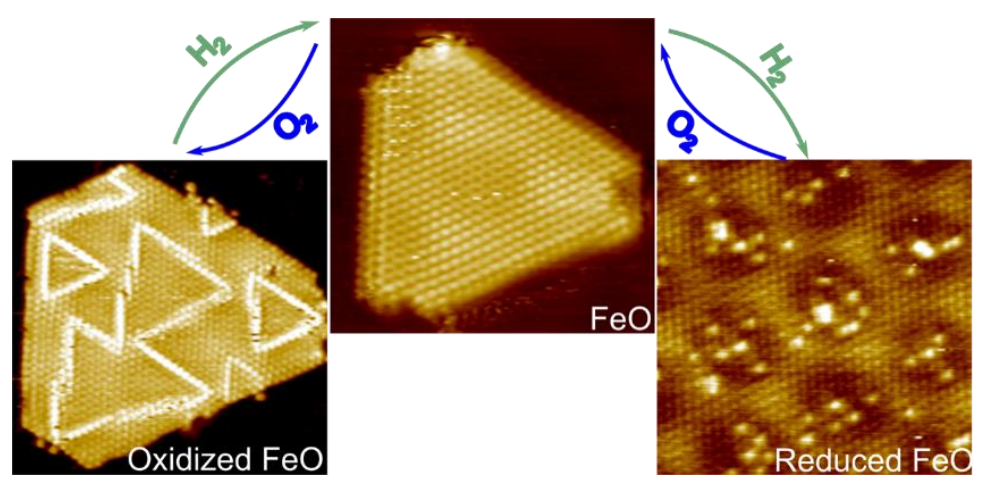

\section{Notes}

The authors declare no competing financial interest. 


\section{Acknowledgement}

This work was supported by the Independent Research Fund Denmark Grant no. 4005-00044B.

We acknowledge the Integrated Materials Research Center (iMAT) at Aarhus University.

\section{References:}

1. Tauster, S. J.; Fung, S. C.; Garten, R. L., Strong Metal-Support Interactions - Group-8 Noble-Metals Supported on $\mathrm{TiO}_{2}$. J. Am. Chem. Soc. 1978, 100, 170-175.

2. Bond, G. C.; Thompson, D. T., Catalysis by Gold. Catal. Rev. 1999, 41, 319-388.

3. Meyer, R.; Lemire, C.; Shaikhutdinov, S. K.; Freund, H., Surface Chemistry of Catalysis by Gold. Gold Bull. 2004, 37, 72-124.

4. Ertl, G., Reactions at Surfaces: From Atoms to Complexity (Nobel Lecture). Angew. Chem.-Int. Edit. 2008, 47, 3524-3535.

5. Fu, Q.; Li, W.-X.; Yao, Y.; Liu, H.; Su, H.-Y.; Ma, D.; Gu, X.-K.; Chen, L.; Wang, Z.; Zhang, H.; Wang, B.; Bao, X., Interface-Confined Ferrous Centers for Catalytic Oxidation. Science 2010, 328, 1141-1144.

6. Guo, X. G.; Fu, Q.; Ning, Y. X.; Wei, M. M.; Li, M. R.; Zhang, S.; Jiang, Z.; Bao, X. H., Ferrous Centers Confined on Core-Shell Nanostructures for Low-Temperature CO Oxidation. J. Am. Chem. Soc. 2012, 134 (30), 12350-12353.

7. Nilius, N., Properties of Oxide thin Films and their Adsorption Behavior Studied by Scanning Tunneling Microscopy and Conductance Spectroscopy. Surf. Sci. Rep. 2009, 64, 595-659.

8. Surnev, S.; Fortunelli, A.; Netzer, F. P., Structure-Property Relationship and Chemical Aspects of Oxide-Metal Hybrid Nanostructures. Chem. Rev. 2013, 113, 4314-4372.

9. $\quad$ Rodriguez, J. A.; Liu, P.; Graciani, J.; Senanayake, S. D.; Grinter, D. C.; Stacchiola, D.; Hrbek, J.; Fernandez-Sanz, J., Inverse Oxide/Metal Catalysts in Fundamental Studies and Practical Applications: A Perspective of Recent Developments. J. Phys. Chem. Lett. 2016, 7, 2627-2639.

10. Zhang, J.; Medlin, J. W., Catalyst Design Using an Inverse Strategy: From Mechanistic studies on inverted model catalysts to applications of oxide-coated metal nanoparticles. Surf. Sci. Rep. 2018, 73, 117-152.

11. Yao, Y. X.; Fu, Q. A.; Wang, Z.; Tan, D. L.; Bao, X. H., Growth and Characterization of Two-Dimensional FeO Nanoislands Supported on Pt(111). J. Phys. Chem. C 2010, 114, 17069-17079.

12. Fu, Q.; Yang, F.; Bao, X. H., Interface-Confined Oxide Nanostructures for Catalytic Oxidation Reactions. Acc. Chem. Res. 2013, 46, 1692-1701. 
13. Gu, X. K.; Ouyang, R. H.; Sun, D. P.; Su, H. Y.; Li, W. X., CO Oxidation at the Perimeters of an $\mathrm{FeO} / \mathrm{Pt}(111)$ Interface and how Water Promotes the Activity: A First-Principles Study. ChemSusChem 2012, 5, 871-878.

14. Sun, D. P.; Gu, X.-K.; Ouyang, R. H.; Su, H. Y.; Fu, Q.; Bao, X. H.; Li, W.-X., Theoretical Study of the Role of a Metal-Cation Ensemble at the Oxide-Metal Boundary on CO Oxidation. J. Phys. Chem. C 2012, 116, 7491-7498.

15. Fu, Q.; Yao, Y. X.; Guo, X. G.; Wei, M. M.; Ning, Y. X.; Liu, H. Y.; Yang, F.; Liu, Z.; Bao, X. H., Reversible Structural Transformation of $\mathrm{FeO}_{\mathrm{x}}$ Nanostructures on Pt under Cycling Redox Conditions and its Effect on Oxidation Catalysis. Phys. Chem. Chem. Phys. 2013, 15, 14708-14714.

16. Ning, Y. X.; Wei, M. M.; Yu, L.; Yang, F.; Chang, R.; Liu, Z.; Fu, Q.; Bao, X. H., Nature of Interface Confinement Effect in Oxide/Metal Catalysts. J. Phys. Chem. C 2015, $119,27556-27561$.

17. Zeuthen, H.; Kudernatsch, W.; Merte, L. R.; Ono, L. K.; Lammich, L.; Besenbacher, F.; Wendt, S., Unraveling the Edge Structures of Platinum(111)-Supported Ultrathin FeO Islands: The Influence of Oxidation State. ACS Nano 2015, 9, 573-583.

18. Kudernatsch, W.; Peng, G. W.; Zeuthen, H.; Bei, Y. H.; Merte, L. R.; Lammich, L.; Besenbacher, F.; Mavrikakis, M.; Wendt, S., Direct Visualization of Catalytically Active Sites at the FeO-Pt(111) Interface. ACS Nano 2015, 9, 7804-7814.

19. Merte, L. R.; Bai, Y. H.; Zeuthen, H.; Peng, G. W.; Lammich, L.; Besenbacher, F.; Mavrikakis, M.; Wendt, S., Identification of O-Rich Structures on Platinum(111)Supported Ultrathin Iron Oxide Films. Surf. Sci. 2016, 652, 261-268.

20. Chen, H.; Liu, Y.; Yang, F.; Wei, M. M.; Zhao, X. F.; Ning, Y. X.; Liu, Q. F.; Zhang, Y.; Fu, Q.; Bao, X. H., Active Phase of $\mathrm{FeO}_{\mathrm{x}} /$ Pt Catalysts in Low-Temperature CO Oxidation and Preferential Oxidation of CO Reaction. J. Phys. Chem. C 2017, 121, 1039810405.

21. Liu, Y.; Ning, Y. X.; Yu, L.; Zhou, Z. W.; Liu, Q. F.; Zhang, Y.; Chen, H.; Xiao, J. P.; Liu, P.; Yang, F.; Bao, X. H., Structure and Electronic Properties of Interface-Confined Oxide Nanostructures. ACS Nano 2017, 11, 11449-11458.

22. Weng, X. F.; Zhang, K.; Pan, Q. S.; Martynova, Y.; Shaikhutdinov, S.; Freund, H. J., Support Effects on CO Oxidation on Metal-Supported Ultrathin FeO(111) Films. Chemcatchem 2017, 9, 705-712.

23. Zhang, K.; Li, L. F.; Shaikhutdinov, S.; Freund, H. J., Carbon Monoxide Oxidation on Metal-Supported Monolayer Oxide Films: Establishing Which Interface is Active. Angew. Chem.-Int. Edit. 2018, 57, 1261-1265.

24. Merte, L. R.; Heard, C. J.; Zhang, F.; Choi, J.; Shipilin, M.; Gustafson, J.; Weaver, J. F.; Grönbeck, H.; Lundgren, E., Tuning the Reactivity of Ultrathin Oxides: NO Adsorption on Monolayer FeO(111). Angew. Chem.-Int. Edit. 2016, 55, 9267-9271.

25. Khan, N. A.; Matranga, C., Nucleation and Growth of Fe and FeO Nanoparticles and Films on Au(111). Surf. Sci. 2008, 602, 932-942.

26. Deng, X. Y.; Lee, J.; Wang, C. J.; Matranga, C.; Aksoy, F.; Liu, Z., In Situ Observation of Water Dissociation with Lattice Incorporation at FeO Particle Edges Using Scanning Tunneling Microscopy and X-ray Photoelectron Spectroscopy. Langmuir 2011, 27, 21462149. 
27. Yu, L.; Liu, Y.; Yang, F.; Evans, J.; Rodriguez, J. A.; Liu, P., CO Oxidation on GoldSupported Iron Oxides: New Insights into Strong Oxide-Metal Interactions. J. Phys. Chem. C 2015, 119, 16614-16622.

28. Weiss, W.; Ranke, W., Surface Chemistry and Catalysis on Well-Defined Epitaxial IronOxide Layers. Prog. Surf. Sci. 2002, 70, 1-151.

29. Kim, Y. J.; Westphal, C.; Ynzunza, R. X.; Galloway, H. C.; Salmeron, M.; VanHove, M. A.; Fadley, C. S., Interlayer Interactions in Epitaxial Oxide Growth: $\mathrm{FeO}$ on Pt(111). Phys. Rev. B 1997, 55, 13448-13451.

30. Zeuthen, H.; Kudernatsch, W.; Peng, G. W.; Merte, L. R.; Ono, L. K.; Lammich, L.; Bai, Y. H.; Grabow, L. C.; Mavrikakis, M.; Wendt, S.; Besenbacher, F., Structure of Stoichiometric and Oxygen-Rich Ultrathin $\mathrm{FeO}(111)$ Films Grown on $\mathrm{Pd}(111)$. J. Phys. Chem. C 2013, 117, 15155-15163.

31. Wöll, C.; Chiang, S.; Wilson, R. J.; Lippel, P. H., Determination of Atom Positions at Stacking-Fault Dislocations on Au(111) by Scanning Tunneling Microscopy. Phys. Rev. B 1989, 39, 7988-7991.

32. Barth, J. V.; Brune, H.; Ertl, G.; Behm, R., Scanning Tunneling Microscopy Observations on the Reconstructed $\mathrm{Au}(111)$ surface: Atomic Structure, Long-Range Superstructure, Rotational Domains, and Surface Defects. Phys. Rev. B 1990, 42, 9307-9317.

33. Johansson, N.; Merte, L. R.; Grånäs, E.; Wendt, S.; Andersen, J. N.; Schnadt, J.; Knudsen, J., Oxidation of Ultrathin $\mathrm{FeO}(111)$ Grown on Pt(111): Spectroscopic Evidence for Hydroxylation Top. Catal. 2016, 59, 506-515.

34. Merte, L. R.; Knudsen, J.; Grabow, L. C.; Vang, R. T.; Lægsgaard, E.; Mavrikakis, M.; Besenbacher, F., Correlating STM Contrast and Atomic-Scale Structure by Chemical Modification: Vacancy Dislocation Loops on FeO/Pt(111). Surf. Sci. 2009, 603, L15-L18.

35. Knudsen, J.; Merte, L. R.; Grabow, L. C.; Eichhorn, F. M.; Porsgaard, S.; Zeuthen, H.; Vang, R. T.; Lægsgaard, E.; Mavrikakis, M.; Besenbacher, F., Reduction of FeO/Pt(111) Thin Films by Exposure to Atomic Hydrogen. Surf. Sci. 2010, 604, 11-20.

36. Kyhl, L.; Bisson, R.; Balog, R.; Groves, M. N.; Kolsbjerg, E. L.; Cassidy, A. M.; Jorgensen, J. H.; Halkjaer, S.; Miwa, J. A.; Cabo, A. G.; Angot, T.; Hofmann, P.; Arman, M. A.; Urpelainen, S.; Lacovig, P.; Bignardi, L.; Bluhm, H.; Knudsen, J.; Hammer, B.; Hornekaer, L., Exciting $\mathrm{H}_{2}$ Molecules for Graphene Functionalization. ACS Nano 2018, $12,513-520$.

37. Hall, R. I.; Cadez, I.; Landau, M.; Pichou, F.; Schermann, C., Vibrational-Excitation of Hydrogen via Recombinative Desorption of Atomic-Hydrogen Gas on a Metal-Surface. Phys. Rev. Lett. 1988, 60, 337-340.

38. Eenshuistra, P. J.; Bonnie, J. H. M.; Los, J.; Hopman, H. J., Observation of Exceptionally high Vibrational-Excitation of Hydrogen Molecules Formed by Wall Recombination. Phys. Rev. Lett. 1988, 60, 341-344.

39. Kurtz, R. L.; Henrich, V. E., Surface Electronic-structure and Chemisorption on Corundum Transition-Metal Oxides - Alpha-Fe2O O. Phys. Rev. B 1987, 36, 3413-3421.

40. Huang, W. X.; Ranke, W., Autocatalytic Partial Reduction of $\mathrm{FeO}(111)$ and $\mathrm{Fe}_{3} \mathrm{O}_{4}(111)$ Films by Atomic Hydrogen. Surf. Sci. 2006, 600, 793-802.

41. Chen, H. Y. T.; Giordano, L.; Pacchioni, G., From Heterolytic to Homolytic $\mathrm{H}_{2}$ Dissociation on Nanostructured $\mathrm{MgO}(001)$ Films As a Function of the Metal Support. $J$. Phys. Chem. C 2013, 117, 10623-10629. 
42. Fester, J.; Garcia-Melchor, M.; Walton, A. S.; Bajdich, M.; Li, Z.; Lammich, L.; Vojvodic, A.; Lauritsen, J. V., Edge Reactivity and Water-Assisted Dissociation on Cobalt Oxide Nanoislands. Nat. Commun. 2017, 8, 14169.

43. Lægsgaard, E.; Besenbacher, F.; Mortensen, K.; Stensgaard, I., A Fully Automated, Thimble-Size Scanning Tunnelling Microscope. J. Microsc. 1988, 152, 663-669.

44. Lauritsen, J. V.; Besenbacher, F., Model Catalyst Surfaces Investigated by Scanning Tunneling Microscopy. Adv. Catal. 2006, 50, 97-147.

45. Li, Y. J.; Li, Z. S.; Ahsen, A.; Lammich, L.; Mannie, G. J. A.; Niemantsverdriet, J. W. H.; Lauritsen, J. V., Atomically Defined Iron Carbide Surface for Fischer-Tropsch Synthesis Catalysis. ACS Catal. 2019, 9, 1264-1273. 